\title{
河网水质管理决策支持系统 在引江济太中的应用
}

\author{
翟淑华 \\ (水利部太湖流域管理局，上海 200434)
}

\begin{abstract}
提 要 利用太湖流域河网水质管理决策支持系统(TAIHU DSS) ,对 2000 年夏季 望虞河应急调水进行了技术方案比较、论证, 重点对望虞河引江应急调水过程中, 常熟枢 纽洜站运用、望虞河东岸分流与否及望虞河立交开闸前对底水的处理等不同条件下的望 虞河入湖水量、水质等进行多方案比较, 为望虞河启用洜站调水、东岸适当分流、先打开蟙 河船闸处理望虞河底水的方案提供了决策的技术依据 ,并引发了对太湖流域引江济太工 作的进一步深入研究和实践, 是决策支持系统在实际工作中的成功应用之一.

关键词 太湖流域 决策支持系统 应急调水

分类号 TP319
\end{abstract}

太湖流域是典型的平原水网地区, 河网密布, 水流坡降极缓, 又受长江口与钱塘江口潮汐 的影响, 河湖水文情势十分复杂, 水流往复不定, 人类生活和生产活动排出的污染物在河流中 往复流动, 长时间在流域内滞留, 增加了水污染治理的难度.2000 年夏季,太湖流域偏旱,太湖 发生了大面积蓝藻爆发, 使太湖供水水质受到影响,如何利用现有的水利工程, 通过调度使符 合饮用水条件的长江水进入太湖, 抑制太湖蓝藻爆发, 望虞河因其直接连接太湖和长江且与运 河立交而成为应急调水入太湖的首选河道. 本文利用太湖流域河网水质管理决策支持系统， 简称 TAIHU DSS(下同)，对望虞河应急调水的主要闸门进行了不同调度方案的模拟计算和分 析研究, 为 2000 年望虞河应急调水方案的制定、为太湖流域引江济太进一步的深入研究与管 理提供了技术依据.

\section{TAIHU DSS 简介}

TAIHU DSS 是一个集数据库、案例管理软件、案例分析软件为一体的模型集成系统, 其核 心为覆盖全流域河流、湖泊 (太湖作为河网边界处理,不包括在 TAIHU DSS 模拟范围之内) 的 河网水量模型、污染负荷模型、水质模型，通过案例管理软件将其有序的组合在一起 ${ }^{[1]}$.各模型 均经过实测资料的率定和验证。

TAIHU DSS 中的数据库包括水量、污染源、水质监测、水质参数及闸门调度等, 可直接通过 人机对话进行编辑修改、完善.

案例管理软件通过人机对话, 可以将数据库中不同的系列资料进行组合、调用, 编辑形成 不同的案例, 然后按照案例管理软件规定的顺序,依次运行污染负荷模型、水量模型、水质模 
型, 计算结果可存成不同的案例供分析比较.每一个案例的计算结果均可以通过图形动态显示 系统直观反映概化河网中任何一条河道的水量、水质逐日动态变化过程，也可以通过案例分析 软件对比分析概化河网中任何一条河道的水量、水质的数值逐日变化过程.

案例分析软件是专门开发用于对数模模拟的各种案例计算结果进行比较、分析的软件工 具, 可对各模拟案例计算结果的逐日变化过程进行对比分析，包括任何一条概化河道的水位、 水量、来水比例、污染负荷的组成及各项水质参数指标，经过定量、直观的对比、分析 根据不同 的管理目的作出科学、可行的方案选择，从而䇥选出对管理者而言最优的方案.

TAIHU DSS 可用于预测在不同水文、调度与污染负荷等条件下，太湖流域概化河网中每 一条河的水位、水量、水质逐日变化过程，及河网中不同水源在河道中组成比例的逐日变化，从 而提出河湖最佳的水量、水质调控措施等, 进行规划方案的研究 ${ }^{[1]}$. TAIHU DSS 建立后 经过进 一步的完善，已成功地应用于太湖流域防洪规划、太湖流域水资源保护规划，及相关的管理、科 研等工作中 提高了决策的速度、实效和精度。

\section{TAIHU DSS 在调水中的应用}

太湖治理是国务院近期重点工作之一 通过水利工程改善水环境的应急措施已引起全社 会广泛关注 ${ }^{[2]} .2000$ 年夏季 ,太湖蓝藻爆发, 对太湖饮用水取水口带来了负面影响 现实对利 用水利工程应急调水提出了迫切要求.望虞河是直接连接长江和太湖的流域性骨干河道 , 又是 流域中唯一与水污染严重的运河立交的河道 ,因而成为应急调水入太湖的首选河道.

望虞河具有行洪、排涝、引水、排涝等多项功能,在不引水的条件下, 望虞河西岸支流流向 为入望虞河, 望虞河及其西岸支流水质较差 , 又无闸门可以控制, 使望虞河应急调水更为困难、 复杂，如何通过水利工程调度，使望虞河应急调水既达到目的又兼顾到地区利益，发挥望虞河 的引水功能, 使长江水通过望虞河进入太湖, 达到阻止太湖水位下降、缓解流域旱情、加快水体 流动、改善太湖及流域水环境的目的 ${ }^{[3 \sim 5]}$,TAIHU DSS 为望虞河应急调水方案的制定提供了多 方案计算、比较分析.

\section{1 计算条件}

设计水文条件 本次计算因模拟干旱条件下的抗旱应急调水，因此在 1971 年实况降雨基 础上, 考虑到 1971 年 5 6 月降雨较大, 调整 5 6 月降雨分配, 分别将降雨为零的极端条件作 为 5 月、6 月降雨的模拟计算条件 其它水文条件包括潮位均采用 1971 年实况.太湖起始水位 采用 $2.88 \mathrm{~m}$.

计算分析时段: 5 月 1 日至 7 月 31 日.工程条件 流域防洪十大骨干工程基本完成后的现 状工程条件，望虞河东岸建有闸门控制，望虞河西岸未建控制工程.计算分析范围 :太湖流域平 原河网, 全流域平原河网共概化为 1328 条河段、973 个节点, 其中湖泊调蓄节点 59 个, , ,门控 制节点 132 个.污染源 污染源及边界浓度值采用 1998 年工业污染源资料.水质条件 计算起 始浓度高锰酸盐指数 $\left(\mathrm{COD}_{\mathrm{Mn}}\right)$ 为 $6 \mathrm{mg} / \mathrm{L}$, 氨氮 $\left(\mathrm{NH}_{3}-\mathrm{N}\right)$ 为 $3 \mathrm{mg} / \mathrm{L}$. 长江边界高锰酸盐指数 $\left(\mathrm{COD}_{\mathrm{Mn}}\right)$ 浓度为 $6 \mathrm{mg} / \mathrm{L}$, 氨氮 $\left(\mathrm{NH}_{3}-\mathrm{N}\right)$ 浓度为 $0.16 \mathrm{mg} / \mathrm{L}$ ，太湖边界高锰酸盐指数 $\left(\mathrm{COD}_{\mathrm{Mn}}\right)$ 浓度为 $6 \mathrm{mg} / \mathrm{L}$, 氨氮 $\left(\mathrm{NH}_{3}-\mathrm{N}\right)$ 浓度为 $0.2 \mathrm{mg} / \mathrm{L}$. 
本次模拟依据 2000 年夏季应急调水一定要使符合标准的长江好水进入太湖、抑制太湖蓝 藻爆发为主要目的, 设计引水计算比较方案为四个.东岸全封闭抽引方案 (方案一)、东岸适当 开启抽引方案 (方案二)、东岸全封闭自引方案 (方案三)及地区引水方案(方案四) (表 1).

表 1 设计方案

Tab.1 Case design

\begin{tabular}{|c|c|c|c|c|}
\hline & 方案一 & 方案二 & 方案三 & 方案四 \\
\hline 望虞河常熟枢纽 & 洜站 $180 \mathrm{~m}^{3} / \mathrm{s}$ & 同方案一 & 自引 & 自引 \\
\hline 望虞河立交 & 洜站启用 $5 \mathrm{~d}$ 后开闸 & 同方案一 & 同方案一 & 关闭 \\
\hline 掻河船闸 & 立交开闸时关闭 & 同方案一 & 同方案一 & 关闭 \\
\hline 望虞河东岸闸门 & 关闭 & 适当开启 & 同方案一 & 同方案－ \\
\hline
\end{tabular}

东岸全封闭抽引方案 (方案一) : 望虞河立交闸门先期关闭 将望虞河本身污水通过蛨河 船闸泄入运河，然后打开望虞河立交闸门 将长江水引入太湖. 望虞河东岸闸门全线关闭，望虞 河常熟枢纽调度依据太湖控制水位，启用常熟枢纽洜站 $180 \mathrm{~m}^{3} / \mathrm{s}$. 常熟枢纽调度运行原则见表 2.沿江其他水闸以规划调度原则控制.该方案考虑望虞河本底污水先期由掻河船闸泄入运河， 因望虞河本底污水是相对太湖水质要求而言，但比该段运河水质好，泄入运河后对运河水质具 有一定的改善作用。

表 2 常熟枢纽调度运行原则

单位 $\mathrm{m}$ ：

Tab.2 The operation of Changshu pumping station on Wangyu river

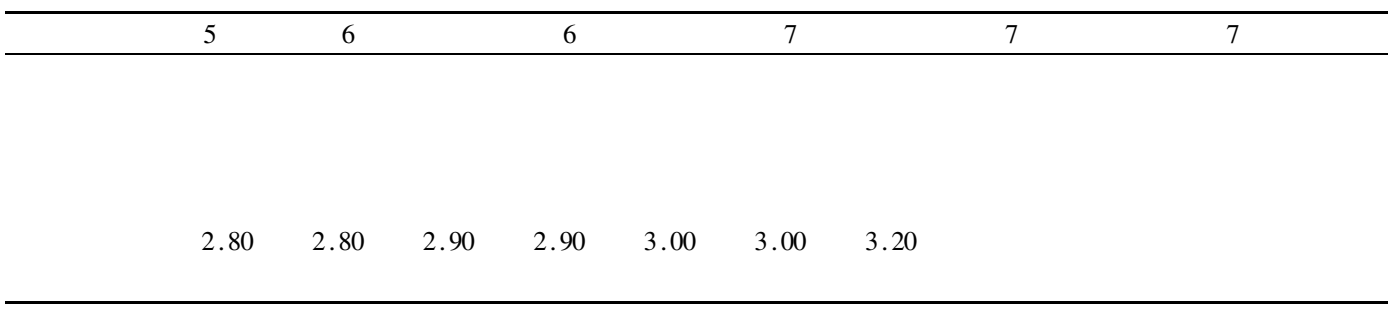

*自引为不启动 $180 \mathrm{~m}^{3} / \mathrm{s}$ 洜站 抽引为启用 $180 \mathrm{~m}^{3} / \mathrm{s}$ 原站引水.

东岸适当开启洜引方案 (方案二)：望虞河东岸个别闸门适当开启,其它条件同方案一.该 方案用于比较望虞河东岸分流对望虞河调引长江水入太湖效率和水质的影响.

东岸全封闭自引方案 (方案三) : 望虞河常熟枢纽利用高潮位自引 (洜站不启用) ,其它条 件同方案一.该方案用于比较望虞河常熟枢纽泉站不启用，仅靠自引对望虞河调引长江水入太 湖效率和水质的影响。

地区引水方案 (方案四)：引水期间望虞河立交、蛊河船闸、望虞河东岸闸门全部关闭，常 熟枢纽利用高潮位自引 (洜站不启用) 其它条件同方案一.该方案因望虞河立交闸门不开,使 望虞河调引的长江水仅对河网起到改善作用，对太湖没有作用，这是地区经常用于改善地区水 环境的办法 故称为地区引水方案.此方案作为望虞河应急调水入太湖方案的对比基础.

2.3 计算结果分析

2.3.1 太湖水位变化 5 月 1 日开始计算，依据表 1 中的设计方案要求和表 2 中望虞河常熟枢 纽的调度运行原则，望虞河常熟枢纽 6 月才开启泉站引水，常熟枢纽洜站启用 $5 \mathrm{~d}$ 后望虞河立 交闸门开启 故不同设计方案 5 月份长江水均没有入太湖, 各方案在 6 月初的太湖水位均约为 
$2.62 \mathrm{~m}$, 在 5 月无降雨的设计水情条件下，一个月后太湖水位将下降 $0.18 \mathrm{~m}$. 按照设计方案, 6 月 望虞河常熟枢纽洜站启用，所有引水入湖方案(方案一、方案二、方案三)均可不同程度地将长 江水调入太湖，比较无长江水调入太湖的地区引水方案(方案四), 在 6 月、7 月同样无降雨的 设计水情条件下，一个月后太湖水位提高 $0.1 \sim 0.12 \mathrm{~m}, 2$ 个月后提高 $0.17 \sim 0.22 \mathrm{~m}$. 无长江水 补给的设计方案四，太湖水位以每月 $0.17 \mathrm{~m}$ 的速度下降,但有长江水补给的设计方案(方案 一、方案二、方案三）即使 6 月滴雨不降太湖水位基本可维持在略高于洜站调水前的水位，6、7 月连续 2 个月没有降雨, 太湖水位也仅略低于洜站调水前水位 $0.02 \sim 0.07 \mathrm{~m}$. 太湖水位变化参 见表 3.说明望虞河立交闸门打开后, 望虞河调引长江水进入太湖, 对维持太湖水位具有十分 有益的作用。

表 3 太湖水位变化一览表

单位 $: m$

Tab.3 Water level of Taihu Lake in different case

\begin{tabular}{cccccc}
\hline & 月.日 & 方案一 & 方案二 & 方案三 & 方案四 \\
\hline \multirow{3}{*}{ 太湖水位 } & 6.1 & 2.62 & 2.61 & 2.62 & 2.62 \\
& 6.30 & 2.67 & 2.66 & 2.65 & 2.55 \\
& 7.31 & 2.60 & 2.58 & 2.55 & 2.38 \\
\hline
\end{tabular}

2.3.2 望虞河引水流量与入湖流量 因不同设计方案在 5 月均为自引条件, 对望虞河引水流 量与入湖流量的分析时段为 $6 \sim 7$ 月. 方案一、方案二在考虑望虞河常熟枢纽抽引条件下,6月 1 日至 7 月 31 日的望虞河日平均引江流量日平均为 $210 \mathrm{~m}^{3} / \mathrm{s}$ 左右 较方案三、方案四闸引方案 增加 $100 \mathrm{~m}^{3} / \mathrm{s}$ 左右 约增加引江流量 50\% 60\% ;同期 ,方案一、方案二入太湖的日平均流量 为 $165 \sim 177 \mathrm{~m}^{3} / \mathrm{s}$ 较方案三自引条件增加 $26 \sim 38 \mathrm{~m}^{3} / \mathrm{s}$, 入湖流量约增加 19\% 27\% , 但同为望 虞河常熟枢纽自引条件, 方案二东岸适当开启后, 望虞河东岸分流使其比方案一较东岸全封闭 条件下日平均减少入湖流量 $12 \mathrm{~m}^{3} / \mathrm{s}$ 约减少入湖流量的 $7 \%$;自引且望虞河东岸闸门全部封闭 的方案一, 望虞河引水的入湖效率约 $85 \%$, 原引且望虞河东岸闸门适当开启的方案二, 望虞河 引水的入湖效率约 $78 \%$ 若仅靠自引而立交同样开启，则望虞河西岸的部分支流依然流入望 虞河，造成望虞河入湖水量大于望虞河引江水量，但因西岸水质污染严重，实际上西岸污水进 入望虞河将造成望虞河水质下降，使望虞河立交闸门不可能正常开启，长江水的入湖效率会更 低.详见望虞河及沿江引水流量与入湖流量一览表(表 4).

表 4 望虞河及沿江引水流量与入湖流量一览表

Tab.4 Water quantity of Wangyu river drawing from Yangtze and to Taihu Lake

\begin{tabular}{ccccc}
\hline 日平均 & 方案一 & 方案二 & 方案三 & 方案四 \\
\hline 望虞河引江段日平均流量 $\left(\mathrm{m}^{3} / \mathrm{s}\right)$ & 208 & 210 & 109 & 81 \\
望虞河入湖段日平均流量 $\left(\mathrm{m}^{3} / \mathrm{s}\right)$ & 177 & 165 & 139 & 0 \\
入湖段占引江段 $(\%)$ & 85 & 78 & & \\
\hline
\end{tabular}

2.3.3 望虞河入湖段水质变化 依据计算条件，望虞河立交闸门在 6 月才开始运行，对望虞河 入湖段水质的分析时段为 $6 \sim 7$ 月 ,分析指标为高锰酸盐指数 $\left(\mathrm{COD}_{\mathrm{Mn}}\right)$ 、氨氮 $\left(\mathrm{NH}_{3}-\mathrm{N}\right)$. 该两项 指标的浓度计算结果表明(表 5) 虽然望虞河西岸没有闸门控制，但在望虞河常熟枢纽洜站引 水的条件下，可以通过抬高望虞河水位使望虞河西岸支流以出望虞河为主，减少望虞河西岸污 
水进入望虞河的量，使望虞河入太湖的水质基本满足太湖饮用水水源地的要求，但仅靠望虞河 常熟枢纽自引，望虞河入湖水质很难保证，实际操作中只能依据每日监测资料，通过望虞河立 交闸门的频繁启闭来保证望虞河入湖水质,势必使望虞河引江的入湖效率降低. 望虞河入湖段 水质总体为引水量大, 则水质较好,引水量小则水质略差.使用望虞河常熟枢纽自引方案较自 引方案对望虞河入湖水质更有保证，但费用增加。

\section{表 5 望虞河入湖段水质对比表}

Tab.5 Water quality of Wangyu river entering Taihu Lake

\begin{tabular}{ccccc}
\hline & 方案一 & 方案二 & 方案三 & 方案四 \\
\hline $\begin{array}{c}\mathrm{COD}_{\mathrm{Mn}} \\
\text { 日平均浓度 }(\mathrm{mg} / \mathrm{L})\end{array}$ & 4.6 & 6.3 & 6.8 & \\
$\mathrm{NH}_{3}-\mathrm{N}$ 日平均浓度 & 0.5 & 0.7 & 0.9 & \\
\hline
\end{tabular}

* 因方案四望虞河立交始终处于关闭状态 故不参与对比分析.

\section{4 结论}

模拟结果说明 采用合理的工程调度手段, 通过望虞河将符合标准的长江好水引入太湖是 可行的，而且对在枯水期维持太湖水位、改善太湖水环境是十分必要的.

综合考虑流域与区域对水量的需求关系，引水对水量与水质的影响 采用文中的设计方案 二 将更易于被各方接受.虽然在 2000 年的实际操作中，因常熟枢纽洜站的运行费用无法落实 而采用望虞河利用长江高潮位自引的应急调水措施，入湖效率仅 $48 \%$,但 2000 年的应急调水 首次实现了长江水直接调入太湖，对太湖蓝藻的爆发起到明显的抑制作用，太湖贡湖湾水体水 质从引水前的劣于 $V$ 类改善为引水后的 II 类. 并且该方案成为《太湖流域引江济太试验工程实 施方案》编制的基本依据，并在 2002 年初付诸实施.

在 TAIHU DSS 应用过程中，对数据库进行了更新，对模型进行了进一步的验证.但在应用 TAIHU DSS 过程中也发现，由于太湖流域河网污染以有机污染为主，对河网水质指标的模拟以 高锰酸盐指数 $\left(\mathrm{COD}_{\mathrm{Mn}}\right)$ 、氨氮 $\left(\mathrm{NH}_{3}-\mathrm{N}\right)$ 为主, 而没有考虑总磷 $(\mathrm{TP})$ 的模拟, 具有一定的局限性， 另外现有的水量水质模型通过数据交换连接无法将水质指标作为水量模型的调度运行指标. 若今后将水质指标作为调度指标，则水量与水质模型的连接需进一步完善.

致谢在计算方案设计和闸门调度运行文件的编制过程中，得到了太湖流域管理局防 办吴浩云主任 林荷娟高级工程师的帮助，在此一并感谢。

\section{参 考 文 献}

1 陈荷生, 秦佩英.太湖流域河网水质和水环境管理研究简介. 水资源保护, 1997 3(1) 5 7

2 朱 威, 李幼芬. 改善太湖流域水环境的水利工程措施设想. 水资源保护, 1996, 12(4) :8 11

3 吴泰来.太湖流域 1999 年特大洪水和对防洪规划的思考.湖泊科学 ,2000 12(1) :6 11

4 阎水玉, 王祥荣.流域生态学与太湖流域防洪、治污及可持续发展.湖泊科学, 2001 ,13(1) :1～8

5 翟淑华 郭孟朴. 望虞河引水对太湖影响前景分析.水资源保护, 1996,12(4) :12 15 


\title{
Application of Taihu Basin Water Quality Management Decision Support System
}

\author{
ZHAI Shuhua \\ ( Taihu Basin Authority 388 Yixian Road, Shanghai 200434 , P. R. China)
}

\begin{abstract}
Taihu Basin water quality management decision support system (Taihu DSS) was developed for water quality management of river network in Taihu Basin. In the summer of 2000 algal blooms occured in Taihu Lake. Wangyu river was considered as the pilot river drawing water from the Yangtze River to Taihu Lake to solve the problem under emergancy time. So Taihu DSS was used to study the technique scenarios for drawing water from the Yangtze River to Taihu Lake through Wangyu river in different ways. To compare with the water quantity and water quality of Wangyu river entering Taihu Lake in different scenarios , the scenario that Wangyu river waster water was discharged through Li river gate into Grand Channel was adopted, which made Wangyu river drawing water from the Yangtze River to Taihu lake successfully in 2000 , and deepened further research and the test.
\end{abstract}

Keywords :Taihu Basin , decision support system , drawing water under emergency 